\title{
Impact of cereal diseases on the qualitative traits of spring barley breeding lines
}

\author{
Bogna Zawieja ${ }^{1}$, Ewa Bakinowska², Andrzej Bichoński ${ }^{3}$, \\ Wiesław Pilarczyk ${ }^{1}$ \\ ${ }^{1}$ Department of Mathematical and Statistical Methods, Poznań University of Life Sciences, \\ Wojska Polskiego 28, 60-637 Poznań, Poland, e-mail: bogna13@up.poznan.pl \\ ${ }^{2}$ Institute of Mathematics, Poznan University of Technology, Piotrowo 3A, \\ 60-965 Poznan, Poland, \\ ${ }^{3}$ Malopolska Breeding Company Polanowice, Zbożowa 4, 30-002 Kraków, Poland
}

\begin{abstract}
SUMMARY
The differences between individual breeding lines of spring barley and a control variety were tested in terms of several measured (continuous) and qualitative traits. The impact of the qualitative traits (diseases) on the quantitative traits, especially yield, was assessed on the basis of the significance of differences for both qualitative traits and yield. Depending on the type of trait, either a logistic model or analysis of variance was used as a statistical tool. The statistically significant differences between some breeding lines and the control variety were shown. It was observed that in fodder barley both infection by mildew and lodging influenced yield. The results of analyses obtained in the so-called pre-preliminary trials and preliminary trials were different. This fact confirmed the necessity of repeating trials over several years.
\end{abstract}

Key words: analysis of variance, breeding, diseases, lodging, logistic model, yield

\section{Introduction}

The breeding trials were carried out continuously over years. At the early stages of cereal breeding, many lines were sown in one-replicate experiments. Then the selected lines were sown in trials with several replications in more than one location, in the so-called pre-preliminary and preliminary trials. Finally, some of the lines were submitted for a registry study, which was carried out in accordance with the UPOV (International Union for the Protection of New Varieties of Plants) convention. In order to evaluate new lines, measurements 
and observations of various traits were performed. These traits included some continuous (measured) traits such as yield, thousand-grain weight and height of plants, and some qualitative traits such as susceptibility to diseases or lodging. In this study experiments conducted with the breeding lines of spring barley, and two types of diseases of that species, powdery mildew and barley net blotch, were considered.

Powdery mildew of barley caused by the fungus Blumeria graminis (DC.) Golovin ex Speerf. Sp. hordei (synonym of Erysiphe graminis DC. f. Sp. Hordei Em Marchal) occurs commonly in the main areas of cultivation of the species in the world. In most European countries the occurrence of powdery mildew causes serious losses in yield and significantly reduces quality (Czembor and Czembor, 2004). This disease is less important in economic terms only in the north and south of the continent. The greatest losses in yield caused by this disease occur in Central Europe, where they can be as high as $10 \%$, and in some areas can reach $25 \%$. It also significantly affects the quality of grain, particularly by reducing the thousand-seed weight, an important feature in the production of malting barley.

Barley net blotch is now regarded as the most dangerous disease of winter barley and spring barley. It is caused by fungi: Pyrenophora teres (Died.) Drechsler - perfect stage, ascus stage; and Drechslera teres (Sacc.) Shoemaker (syn. Helminthosporium teres Sacc.) - conidial stage. Infection may be present in all stages of the plant's development. The disease occurs in different aboveground parts of plants, most often in the leaves. Symptoms occur throughout the barley growing season (from the seedling stage to full maturity). The pathogen infects mainly leaves and leaf sheath, but it can also occur on stems and spikes. It is characterized by great diversity. The effect of this pathogen on different barley varieties was evaluated here.

The aforementioned traits were measured and evaluated on data from prepreliminary and preliminary breeding experiments with breeding lines of malting and fodder barley. The statistical significance of differences between breeding lines and the control variety were tested. For this purpose the ANOVA 
method and logistic models were used. The use of logistic models was reported by Bakinowska and Kala (2007) in an analysis of data concerning the lodging of pea varieties. Mila et al. (2004) applied a fixed logistic model to develop explanatory models of Sclerotinia stem rot prevalence (for soybean) in four states of the northern-central part of the United States. A fixed logistic model was applied by Bakinowska et al. (2012) in statistical analysis of downy mildew infection data in field pea varieties. A more general mixed logistic model was applied by Bakinowska et al. (2016), also for downy mildew data in pea.

The aim of this study was to indicate methods for the selection of lines that differ significantly from the control variety in terms of both qualitative and quantitative traits. Additionally the impact of the disease and lodging on yield was analyzed. For this purpose the logistic model was used for data recorded with the use of an ordered scale.

\section{Material and methods}

\subsection{Experimental data.}

Three two-year series of experiments with breeding lines of fodder spring barley and malting spring barley were performed at crop breeding stations in Poland. The first series was carried out in 2009-2010, the second in 2011-2012 and the third in 2012-2013. In each series, both pre-preliminary trials (PP) and preliminary trials (WP) were conducted. The second (2011-2012) and the third (2012-2013) series were repeated in several locations (PP trials - 2011 and 2012 - were conducted in five locations, and WP trials - 2012 and 2013 - in six locations), while the first trial series (PP 2009 and WP 2010) was conducted only in one location. A single trial (one location and one year of tests) was conducted in incomplete block designs with three replications. The incomplete blocks consisted of 6 to 7 plots in trials with fodder barley and of 7 to 8 in trials with malting barley. Different numbers of breeding lines were sown in various experiments (Table 1). The lines sown in the second year (WP) were selected from the lines examined in the first year (PP). Malting barley and fodder barley 
were sown in one experiment, which was organized in such a way that they can be considered either jointly or as separate experiments.

Table 1. Numbers of examined lines in the pre-preliminary trial (PP) and preliminary trial (WP) for fodder and malting barley

\begin{tabular}{c|cccccc}
\hline $\begin{array}{c}\text { Year } \\
\text { Trial }\end{array}$ & $\begin{array}{c}2009 \\
\text { PP }\end{array}$ & $\begin{array}{c}2010 \\
\text { WP }\end{array}$ & $\begin{array}{c}2011 \\
\text { PP }\end{array}$ & $\begin{array}{c}2012 \\
\text { WP }\end{array}$ & $\begin{array}{c}\text { PP } \\
\text { WP }\end{array}$ \\
\hline Fodder barley & 72 & 38 & 76 & 45 & 85 & 45 \\
Malting barley & 60 & 21 & 41 & 28 & 39 & 30 \\
\hline
\end{tabular}

Each of the three two-year periods (2009-2010, 2011-2012, 2012-2013) differed in terms of the lines examined. Only three control varieties were repeated, though not in all cases. The control varieties were Blask, Suweren and Conchita from 2009 until 2012, and Olympic, Suweren and either Soldo (in the fodder barley trials) or Blask (in the malting barley trials) in 2013. Moreover, some of the examined lines were sown only in one year of the two-year testing period (which is due to the specific nature of the breeding research).

In each trial several traits were observed, the number of which was dependent on whether or not the disease emerged in a given year. Diseases considered included leaf rust, net blotch, leaf septoria, powdery mildew and scald. Moreover, traits such as lodging, the number of days from January 1 to the date of ear emergence, height of plants, weight of one thousand grains and yield were studied in the trials.

In this study the set of locations is restricted to those in which trials were carried out in both years. Moreover, from all observed traits, three qualitative and three quantitative traits were chosen for detailed analysis. In addition, the set of analyzed lines was limited to those that had been sown in both years of twoyear periods. For the purposes of this study only one control variety, having the best results in terms of both the quantitative and qualitative traits (the highest yield, no lodging and no diseases), was selected. From 2009 to 2012 this was Conchita, and in 2013 Olympik. 
As mentioned above, from all the qualitative traits, three were selected for detailed analysis (severity of powdery mildew and net blotch and tendency for lodging). All of the qualitative traits were expressed in a 9-point bonitation scale: 9 meant that the plot was assigned to the best category (no disease or lodging observed), while 1 denoted the total infection of plants (or plant completely lodged). Because of the large number of categories and small number of observations, nine disjoint categories were combined into three, namely: category 1 represented the worst situation on the plot, 2 the average, and 3the best (healthy plants and no lodging observed).

All of the quantitative traits measured in these trials were included in the analysis. The yield was measured in decitonnes per hectare [dt/ha] after conversion to a standard humidity of 15\%, 1000-grain weight was determined in grams $[\mathrm{g}]$, and height was expressed in centimeters $[\mathrm{cm}]$ when plants reached full maturity.

\subsection{Statistical methods.}

Analyses were conducted for two-year periods (mixed model) taking into account the random effect of years, and also separately for each year (fixed model).

\section{Qualitative traits}

For the analysis of one-year data results, the fixed logistic model was used (Rao and Toutenburg 1999):

$$
\log \frac{p}{1-p}=\beta_{0}+\beta_{i}
$$

where $p$ denotes the probability of occurrence of disease or of lodging, $\beta_{i}$ is the fixed effect of the $i$-th genotype, and $\beta_{0}$ is the intercept.

The probability of a given category occurring, calculated from (1), may be written in the form

$$
p=\frac{\exp \left(\beta_{0}+\beta_{i}\right)}{1+\exp \left(\beta_{0}+\beta_{i}\right)} .
$$


For two-year data the mixed logistic model was used:

$$
\log \frac{p}{1-p}=\beta_{0}+\beta_{i}+\gamma_{j}
$$

where $p$ (as previously) denotes the probability of occurrence of disease or of lodging, $\gamma_{j}$ is a random effect of the $j$-th year, and $\beta_{i}$ and $\beta_{0}$ are as above.

\section{Quantitative traits}

In the analysis of the results of one-year observations, the fixed model of ANOVA was used:

$$
y_{i j}=\mu+\tau_{i}+e_{i j}
$$

where $y_{i j}$ denotes the observation of the $i$-th genotype in the $j$-th replication, $\mu$ is the overall mean, $\tau_{i}$ is the fixed effect of the $i$-th genotype, and $e_{i j}$ is a random error (assumed to be normally distributed with mean 0 and variance $\sigma^{2}$ ).

In the analysis of the results for each two-year period, the mixed model was used, analogously to (3), but here the interaction effect was added:

$$
y_{i j k}=\mu+\tau_{i}+\beta_{j}+\eta_{i j}+e_{i j k},
$$

where $y_{i j k}$ is the observation concerning the $i$-th genotype in the $j$-th year of study in the $k$-th replication, $\beta_{j}$ is the random effect of the $j$-th year, $\eta_{i j}$ is the interaction of the $i$-th genotype with the $j$-th year, $e_{i j k}$ is the random error (with expectation 0 and variance $\sigma^{2}$ ), and $\mu$ and $\tau_{i}$ are as above.

\section{Results}

To avoid non-orthogonality in each analyzed series the number of locations was constrained to five and only genotypes that occurred in both years were included.

On the basis of the performed analysis the lines differing significantly (at $\alpha=0.1, \alpha=0.05$ and $\alpha=0.01$ ) from the control, for at least one of the studied traits, were identified. This was done in each trial separately and next in each two-year periods. Since special attention was paid to genotypes for which 
significant differences were found both for qualitative traits and for yield, only the results for which such differences were detected will be discussed.

In the 2009-2010 and 2011-2012 periods (Table 2 and 3) the severity of powdery mildew infection was higher in the fodder barely lines than in the control. However, in the 2012-2013 period the malting barley lines were

Table 2. Selected genotypes that differed significantly from the control variety in the 2009-2010 period

\begin{tabular}{|c|c|c|c|c|c|c|c|c|c|c|}
\hline \multicolumn{2}{|l|}{ Trait } & \multicolumn{3}{|c|}{ Powdery mildew } & \multicolumn{3}{|c|}{ Net blotch } & \multicolumn{3}{|c|}{ Lodging } \\
\hline \multirow{2}{*}{\multicolumn{2}{|c|}{ Year }} & 2009 & 2010 & $09 /$ & 2009 & 2010 & 09/ & 2009 & 2010 & $09 /$ \\
\hline & & $\mathrm{PP}$ & WP & 10 & $\mathrm{PP}$ & WP & 10 & $\mathrm{PP}$ & WP & 10 \\
\hline \multirow{4}{*}{ 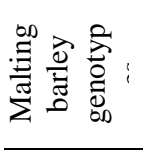 } & & - & - & - & - & - & - & $* \downarrow$ & ${ }^{\mathrm{o}} \uparrow$ & - \\
\hline & & - & - & - & - & - & - & $* \downarrow$ & $\mathrm{o} \uparrow$ & - \\
\hline & & - & - & - & - & $* \uparrow$ & - & - & - & - \\
\hline & & - & - & - & - & - & - & $* * \downarrow$ & - & $* *$ \\
\hline \multirow{7}{*}{ 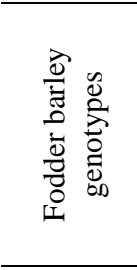 } & & - & ${ }^{\circ} \downarrow$ & - & - & - & - & - & - & - \\
\hline & & - & - & - & - & - & - & $* \uparrow$ & - & - \\
\hline & & - & - & - & - & - & - & $* \uparrow$ & - & $\mathrm{o} \uparrow$ \\
\hline & & - & ${ }^{\circ} \downarrow$ & - & - & - & - & $\mathrm{o} \uparrow$ & $* \downarrow$ & - \\
\hline & & - & $* \downarrow$ & ${ }^{\circ} \downarrow$ & - & - & $* \downarrow$ & $* \uparrow$ & ${ }^{\circ} \downarrow$ & - \\
\hline & & - & $* \downarrow$ & - & - & - & - & - & - & - \\
\hline & & - & $* * \downarrow$ & $* \downarrow$ & - & - & - & - & - & - \\
\hline \multicolumn{2}{|l|}{ Trait } & \multicolumn{3}{|c|}{ Yield } & \multicolumn{3}{|c|}{ 1000-grain wt. } & \multicolumn{3}{|c|}{ Height } \\
\hline \multirow{2}{*}{\multicolumn{2}{|c|}{ Year }} & 2009 & 2010 & $09 /$ & & 2009 & & 2009 & 2010 & $09 /$ \\
\hline & & PP & WP & 10 & & $\mathrm{PP}$ & & PP & WP & 10 \\
\hline \multirow{4}{*}{ 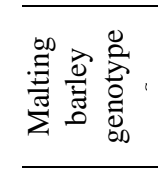 } & 3 & - & $* \downarrow$ & - & & $* * \downarrow$ & & $* * \uparrow$ & $* * \uparrow$ & $* * \uparrow$ \\
\hline & 4 & - & ${ }^{\circ} \downarrow$ & - & & - & & $* * \uparrow$ & - & $\mathrm{o} \uparrow$ \\
\hline & 11 & $* \uparrow$ & $* * \downarrow$ & - & & o $\downarrow$ & & $\mathrm{o} \uparrow$ & - & $* * \uparrow$ \\
\hline & 14 & - & $\circ \downarrow$ & $* \downarrow$ & & $* \downarrow$ & & - & $\mathrm{o} \uparrow$ & $\mathrm{o} \uparrow$ \\
\hline \multirow{7}{*}{ 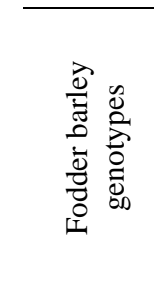 } & 16 & $* \uparrow$ & ${ }^{\circ} \downarrow$ & ${ }^{\circ} \downarrow$ & & $* * \uparrow$ & & $* \uparrow$ & $* * \uparrow$ & $* * \uparrow$ \\
\hline & 18 & - & - & - & & $* * \uparrow$ & & - & $* \uparrow$ & - \\
\hline & 21 & - & $* * \downarrow$ & $* \downarrow$ & & $* * \uparrow$ & & - & $* * \uparrow$ & $* \uparrow$ \\
\hline & 24 & $* \uparrow$ & - & $* \uparrow$ & & $\mathrm{o} \uparrow$ & & $* \uparrow$ & $* * \uparrow$ & $* * \uparrow$ \\
\hline & 27 & - & $* * \downarrow$ & - & & $\mathrm{o} \uparrow$ & & - & $* * \uparrow$ & $* * \uparrow$ \\
\hline & 35 & $* \uparrow$ & $* \downarrow$ & - & & - & & $* * \uparrow$ & $* * \uparrow$ & $* * \uparrow$ \\
\hline & 38 & - & - & - & & - & & $* * \uparrow$ & $* \uparrow$ & $* * \uparrow$ \\
\hline
\end{tabular}


Table 3. Selected genotypes that differed significantly from the control variety in the 2011-2012 period

\begin{tabular}{|c|c|c|c|c|c|c|c|c|c|c|}
\hline Tra & & & y mild & & & blotch & & & lging & \\
\hline Yer & & 2011 & 2012 & $11 /$ & 2011 & 2012 & $11 /$ & 2011 & 2012 & $11 /$ \\
\hline rec & & PP & WP & 12 & PP & WP & 12 & PP & WP & 12 \\
\hline & 22 & - & - & - & - & - & ${ }^{\circ} \downarrow$ & - & - & - \\
\hline$\stackrel{0,0}{=} \vec{a}$ & 24 & - & - & - & - & - & - & - & - & ${ }^{\circ} \downarrow$ \\
\hline E & 25 & - & - & - & - & ${ }^{\circ} \downarrow$ & ${ }^{\circ} \downarrow$ & - & - & - \\
\hline & 26 & - & - & - & - & - & - & - & - & ${ }^{\circ} \downarrow$ \\
\hline & 28 & - & - & - & - & - & - & - & - & ${ }^{\circ} \downarrow$ \\
\hline & 9 & $* \downarrow$ & - & $* \downarrow$ & ${ }^{\circ} \downarrow$ & - & ${ }^{\circ} \downarrow$ & - & - & - \\
\hline$\vec{\Xi} \circlearrowright$ & 11 & $* * \downarrow$ & ${ }^{\circ} \downarrow$ & $* * \downarrow$ & - & - & - & - & - & - \\
\hline$\stackrel{0}{0}$ & 18 & $* \downarrow$ & - & $* \downarrow$ & - & - & - & ${ }^{\circ} \downarrow$ & - & - \\
\hline$\overline{\underline{D}} \stackrel{c}{0}$ & 25 & $* \downarrow$ & - & $* \downarrow$ & - & - & - & - & - & - \\
\hline 8 & 33 & $* * \downarrow$ & ${ }^{\circ} \downarrow$ & $* * \downarrow$ & - & - & ${ }^{\circ} \downarrow$ & - & - & - \\
\hline 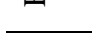 & 43 & ${ }^{\circ} \downarrow$ & ${ }^{\circ} \downarrow$ & $* \downarrow$ & - & - & - & - & - & - \\
\hline Tra & & & ield & & & grain $\mathrm{w}$ & & & ight & \\
\hline Yer & & 2011 & 2012 & $11 /$ & 2011 & 2012 & $11 /$ & 2011 & 2012 & $11 /$ \\
\hline rec & & PP & WP & 12 & $\mathrm{PP}$ & WP & 12 & PP & WP & 12 \\
\hline & 22 & - & - & - & $* * \downarrow$ & $* * \downarrow$ & $* \downarrow$ & - & - & - \\
\hline$\stackrel{\infty}{=} \lambda$ & 24 & - & - & - & $* * \downarrow$ & $* * \downarrow$ & $* * \downarrow$ & - & - & - \\
\hline 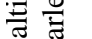 & 25 & - & - & - & $* * \downarrow$ & - & ${ }^{\circ} \downarrow$ & $* * \uparrow$ & $* * \uparrow$ & $\mathrm{o} \uparrow$ \\
\hline$\Sigma 0$ & 26 & - & - & - & $* * \downarrow$ & $* * \downarrow$ & $* * \downarrow$ & $* * \uparrow$ & $* * \uparrow$ & $* \uparrow$ \\
\hline & 28 & - & - & - & $* * \downarrow$ & - & ${ }^{\circ} \downarrow$ & $* * \uparrow$ & $* * \uparrow$ & $* \uparrow$ \\
\hline & 9 & $\mathrm{o} \uparrow$ & - & - & $* * \downarrow$ & $* * \downarrow$ & $* * \downarrow$ & - & $* * \downarrow$ & - \\
\hline$\stackrel{0}{\Xi}$ & 11 & $* \uparrow$ & - & - & - & $* \uparrow$ & ${ }^{o} \uparrow$ & $* * \uparrow$ & $* * \uparrow$ & $* \uparrow$ \\
\hline$\stackrel{0}{0}$ & 18 & - & - & - & $* \downarrow$ & - & ${ }^{\circ} \downarrow$ & $* * \uparrow$ & - & $* \uparrow$ \\
\hline$\overline{\underline{D}} \stackrel{c}{0}$ & 25 & - & - & - & $* * \downarrow$ & ${ }^{\circ} \downarrow$ & $* * \downarrow$ & - & - & - \\
\hline 8 & 33 & $* \uparrow$ & - & - & $* * \downarrow$ & - & $* \downarrow$ & $* * \uparrow$ & - & $* \uparrow$ \\
\hline & 43 & ${ }^{o} \uparrow$ & - & - & $* * \downarrow$ & $* * \downarrow$ & $* * \downarrow$ & $* \uparrow$ & - & - \\
\hline
\end{tabular}

the most infected by powdery mildew (Table 4). The results obtained for each year of research (separately) in the 2009-2010 and 2011-2012 periods coincided with the results obtained in the joint analysis made for these two years of research (using model 3). This means that when in at least one of the two study years (model 1) the tested line was significantly different from the control, then in the whole two-year period (model 3) it was also different from the control.

Significant differences in net blotch occurrence between the individual lines and the control were identified in only a few cases in the single trials. However, most of them were not confirmed in the joint analysis (Tables 2-4). While in the 2009-2010 (malting lines) and 2012-2013 (malting and fodder lines) periods the majority of new genotypes were infected by net blotch to a lesser extent than the 
control variety, the opposite situation was observed in the 2011-2012 period (malting and fodder lines).

Table 4. Selected genotypes that differed significantly from the control variety in the 2012-2013 period

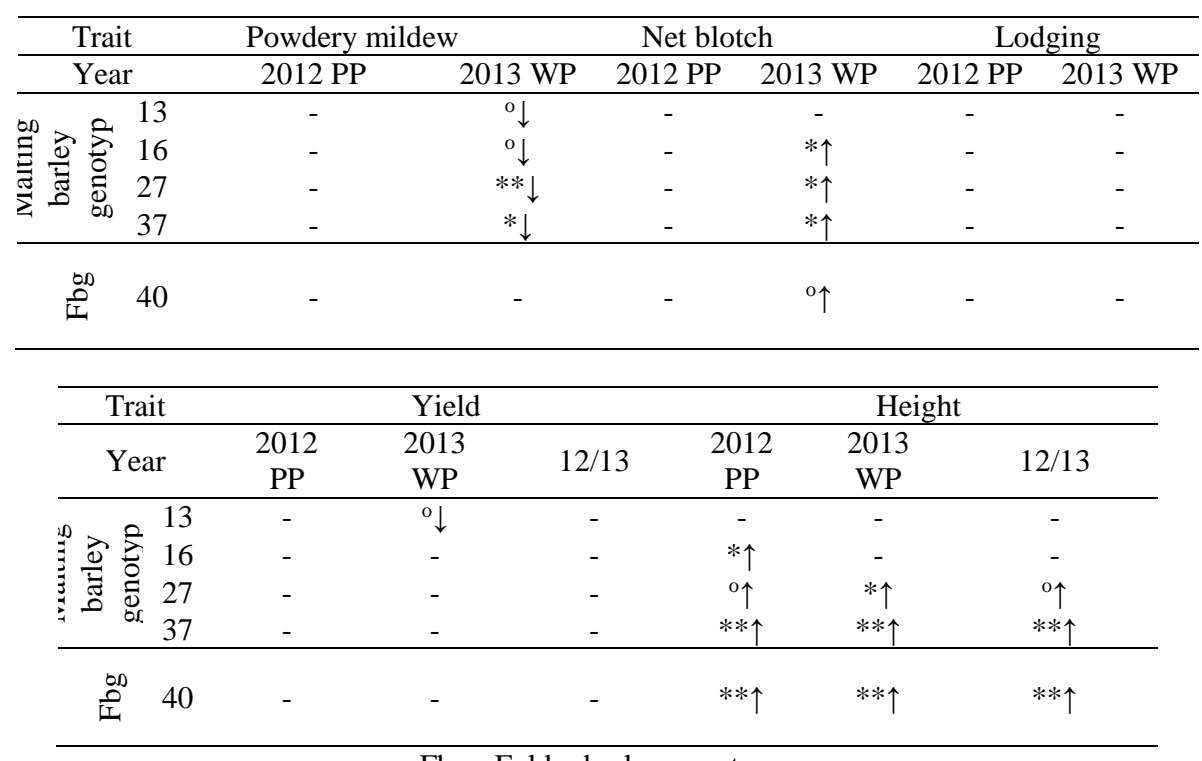

Fbg - Folder barley genotypes

In the case of lodging significant differences were observed chiefly in the first two-year period (2009-2010). This may be due to the fact that this trial was performed in one single location with specific agro-meteorological conditions (possibly unfavorable). In the two succeeding periods (2011-2012, 2012-2013) trials were performed in several locations simultaneously; therefore the risk of the influence of unfavorable conditions in one of those locations on the overall results was decreased. In addition, the results for the quantitative traits in each separate year of study (model 4) were confirmed by the joint analysis made for the two-year periods (model 5), with the exception of fodder barely lines in the 2011-2012 period.

The probability of powdery mildew infection was calculated using formula (2) (see Table 5 and Figure 1). In the case of two traits, lodging and yield, in the first year of research the genotypes exceeded the control, while in the second 
year the opposite situation was observed (see for example malting barley genotypes 3 and 4 in respect of lodging in the 2009-2010 period). These two contrasting situations suggest that there is a need for at least two years of preregistration research. In 2009 the negative influence of lodging on thousandgrain weight was observed (malting genotypes 3 and 14 had lower weights simultaneously with a higher level of lodging). When genotypes were less susceptible to lodging than the control, their thousand-grain weight was higher (fodder genotypes 18, 21, 24, 27). In 2010 powdery mildew infection caused reduction in yield (fodder genotypes 16, 27, 35). However, in 2011 the yield of the genotypes that were more infected by powdery mildew than the control was

Table 5. Estimates of parameters in logistic model (2)

\begin{tabular}{cc|cccc}
\hline \multicolumn{2}{c|}{ Intercept $\beta_{0}$} & \multicolumn{4}{c}{ Effect of $i$-th genotype $\beta_{i}$} \\
\hline \multicolumn{2}{c|}{ Category } & \multicolumn{4}{c}{ Genotype } \\
\hline 1 & 2 & 11 & 25 & 43 & Standard \\
\hline-4.4044 & -1.9598 & 4.0317 & 3.1821 & 2.5660 & 0 \\
\hline
\end{tabular}

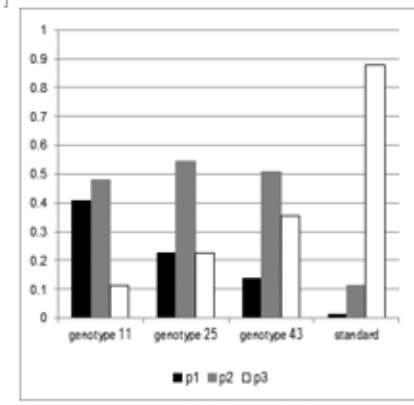

a

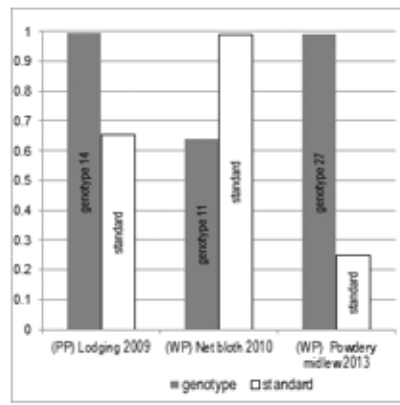

b1

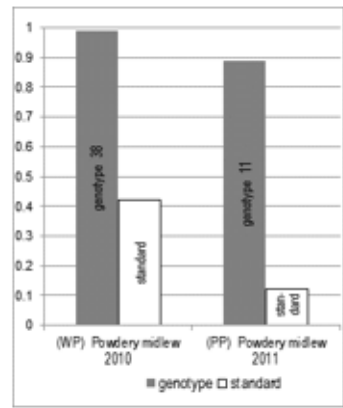

b2

Figure 1. a - Probability of degree of infection by powdery mildew for some genotypes - fodder barley 2011 (p3 - genotype not infected, p1 - genotype the most infected); $b$ - Probabilities of lodging, infection by powdery mildew and net blotch for selected genotypes and for standard variety in multiple years: b1 - malting barley, b2 - fodder barley

not lower than that of the control variety (for genotypes 9, 11, 33, 43 the yield was higher than the control, and for genotypes 18 and 25 it was at the same level). On the other hand, the thousand-grain weight of these genotypes was 
significantly lower than that of the control. In 2012 a similar relationship was observed for genotype 43 in respect of the thousand-grain weight. This relationship was also confirmed for genotypes 9, 18, 25, 33, 43 in the joint analysis made for the 2011-2012 period. The reverse situation occurred with genotype 11, with a higher thousand-grain yield and higher infection by powdery mildew compared with the control variety.

\section{Discussion}

In the paper by Louw et al. (1996) the occurrence of net-type blotch and spottype lesions in South Africa was discussed. A significant influence on the losses in susceptible barley cultivars grown in the Western Cape Province was detected. Bekele et al. (2004) showed that the severity of net blotch was negatively correlated with grain yield and 1000-kernel weight. An assessment of the effects of net blotch disease on malt barley yield and grain quality under natural infection was presented by Galano et al. (2008). In that study, in the case of two tested varieties, losses of yield and thousand-kernel weight were detected. However, the influence was not detected on other analyzed grain quality characteristics. Considerable yield reduction of barley due to net blotch was demonstrated by Khan (1987), Yousfi and Ezzahiri (2001) and Bekele (2005).

In a study by Statkevičiūtė and Leistrumaitè (2010) European commercial cultivars of spring barley were tested in respect of powdery mildew and net blotch resistance. Only varieties with the Mlo resistance gene (which are fully resistant to powdery mildew) were considered. The authors found that resistance genes are losing their effectiveness for most of the varieties because the effectiveness of the Mlo gene depends on other factors (Lyngkjaer et al. 1995). Only the variety 'Acrobat' (resistance gene unknown) exhibited good resistance to powdery mildew and net blotch. It was found that increased net blotch infection had a negative impact on ear length, number of spikelets and number of grains in the ear, in the year 2007. In 2009 no significant effects on these traits were found, but net blotch occurrence caused significantly lower grain weight per ear. 
Leath and Bowen (1989), using a regression approach, showed that powdery mildew caused yield reduction. Czembor and Frese (2003) screened barley landraces collected from Turkey for resistance to powdery mildew.

Kandemir (2004) showed that lodging significantly influenced barley yielding. In the paper by Caierão (2006), irrespective of the year and independently of the lodging intensity, the effects on these variables were similar for different dates of occurrence (from booting until physiological maturity). Based on the results, he stated that ripening was the least sensitive phase to lodging effects, in absolute values of grain yield, followed by heading grain filling.

In the above-mentioned papers, the ANOVA and standard regression models were used as statistical tools for the analysis of qualitative traits. Hampel and Hartmann (2011) used the generalized linear model (under binomial distribution) for data concerning winter hardiness of winter barley. In our approach, a logistic model belonging to the wide class of generalized linear models was applied to the analysis of such traits.

Several authors have applied successfully different types of logistic model for the statistical analysis and interpretation of qualitative traits measured on ordinal scales. Wolf et al. (2003) used a logistic regression model in analyzing experiments on epidemics of Fusarium head blight, which have had a negative influence on wheat production in many regions of North America. A similar model (logistic regression model) was applied by Mila et al. (2004) to estimate the probability of stem rot prevalence with historical disease data from four states of the north-central region of the United States. In a paper by Bakinowska and Kala (2007) a fixed logistic model was applied in the analysis of lodging in pea varieties. The same model was used in a paper by Bakinowska et al. (2012) in analysis of downy mildew infection in field pea trials. Two types of logistic model (fixed and mixed) were applied by Bakinowska et al. (2016) for analysis of downy mildew data on field pea.

Analysis of the extensive trial data leads us to conclude that:

- In the case of two traits, lodging and yield, sometimes opposing tendencies were observed in two years of research - one year some genotypes 
exceeded the standard variety in respect of the tested traits, while in the other year they were worse.

- Infection by powdery mildew in general caused reduction in yield.

- No impact of diseases on plant height was observed.

- The behavior of the observed genotypes with respect to the tested traits was dependent on the environmental conditions in the year of the trial. It is recommended to carry out a series of such experiments over several years.

- The logistic model confirmed its usefulness in analyzing and interpreting quantitative data.

It was observed that powdery mildew and lodging mainly affected the yield of fodder genotypes. In most of the analyzed cases (for qualitative traits and yield) it was noted that the results of the pre-preliminary trials were contradicttory to those of the preliminary trials. This again suggests the need to conduct such trials over multiple years. In most trials with malting genotypes no impact of the qualitative traits on yield was observed. In the case of the malting genotypes the thousand-grain weight was lower than that of the standard variety. In the trials with malting barley as well as with fodder barley the plants of studied genotypes reached a greater height than the plants of the standard variety.

\section{Acknowledgements}

The statistical analysis in presented research was partially funded with grants for education allocated by the Ministry of Science and Higher Education executed under the subject of No 04/43/DSPB/0088

\section{REFERENCES}

Bakinowska E., Kala R. (2007): An application of logistic models for comparison of varieties of seed pea with respect to lodging. Biometrical Letters 44 (2): 143-154.

Bakinowska E., Pilarczyk W., Osiecka A., Wiatr K. (2012): Analysis of downy mildew infection of field pea varieties using the logistic model. Journal of Plant Protection Research 52 (2): 240-246.

Bakinowska E. ,Pilarczyk W., Zawieja B. (2016): Analysis of downy mildew data on field pea an empirical comparison of two logistic models. Acta Agriculturae Scandinavica Section B - Soil and Plant Science 66 (2): 107-116. 
Bekele H. (2005): Infection biology epidemiology and resistance of barley land race lines to Pyrenophorateres. A dissertation submitted in partial fulfillment of the requirements for the Degree of Doctor of Philosophy (Tropical Agriculture). Graduate School Kasetsart University Thailand: 156.

Bekele H., Sangchote S., Sarobol E. (2004): Barley Net Blotch (Pyrenophorateres Drechsl.) Epidemiology \& Management. Kasetsart Journal (Nat. Sci.) 38: 380- 392

Caierão E. (2006): Effect of induced lodging on grain yield and quality of brewing barley. Crop Breeding and Applied Biotechnology 6: 215-221.

Czembor P.Cz., Czembor J.H. (2004): The use of bulk segregant analysisto identify a RAPD marker linked to the Mlalocus of barley. Plant Breeding and Seed Science 49: 41-49.

Czembor J.H., Frese L. (2003): Powdery mildew resistance in selections from barley landraces collected from Turkey. Die Bodenkultur 54: 35-40.

Galano T., Fininsa C. ,Bultosa G. (2008): Effects of Net Blotch (Pyrenophorateres) on Malt Barley Yield and Grain Quality at Holeta Central Etiopia. East African Journal of Science 2 (2): 150-158.

Hampel D., Hartmann J. (2011): Testing frost resistance for cereals in the Czech Republic. Cultivar Testing Bull 33: 83-90.

Kandemir N. (2004): Search for High Yielding Lodging Resistant Barley Cultivars with Satisfactory Straw Yields for a Fertile Production Area of Turkey. Pakistan Journal of Biological Science 7(6): 917-976.

Khan T.N. (1987): Relationship between net blotch (Drechslerateres) and losses in grain yield of barley in Western Australia. Australian Journal of Agricultural Research 38: 671- 679.

Leath S., Bowen K.L. (1989): Effects of powdery mildew triadimenol seed treatment and triadimefon foliar sprays on yield of winter wheat in North Carolina. Phytopathology. 79: 152-155.

Louw J.P., Crous P.W., Holz G. (1996): Relative importance of the barley net blotch pathogens Pyrenophorateres f. teres (net-type) and P. teres f. maculata (spot-type) in South Africa. African Plant Protection 2: 89-95.

Lyngkjaer M.F., Jensen H.P., Ostergard H. (1995): A Japanese powdery mildew isolate with exceptionally large infection efficiency on Mlo-resistant barely. Plant Pathology. 44: 786- 790.

Mila A.L. Carriquiry A.L. Yang X.B. (2004): Modeling the prevalence of Sclerotinia stem rot of soybeans in the North Central region of the United States. Phytopathology. 94: 102-110.

Rao C.R., Toutenburg H. (1999): Linear Models. 2nd ed. Springer-Verlag New York.

Statkevičiūtė G., Leistrumaitė A. (2010): Modern varieties of spring barley as a genetic resource for disease resistance breeding. Agronomy Research 8 (Special Issue III): 721-728.

Wolf E.D., Madden L.V., Lipps P.E. (2003): Risk assessment models for wheat Fusarium head blight epidemics based on withinseason weather data. Phytopathology 93: 428-435.

Yousfi B.E., Ezzahiri B. (2001): Net blotch in semi-arid regions of Morocco. I. Epidemiology. Field Crop Research 73: 35- 46. 